\title{
The Analysis of Scientific and Commercial Softwares Accuracy in GPS Observation Processing
}

\author{
Morteza Hamidi ${ }^{1}$, Peyman Javadi ${ }^{2 *}$ \\ ${ }^{1}$ Master of Geodesy and Lecturer, Islamic Azad University, Rafsanjan Branch, Rafsanjan, Iran \\ ${ }^{2}$ Master of Geodesy, Lecturer and Head of Department of Geomatics Engineering at Sama College, Ardabil Branch, Ardabil, Iran \\ Email: *peymanjavadi@samaard.ac.ir
}

How to cite this paper: Hamidi, M. and Javadi, P. (2017) The Analysis of Scientific and Commercial Softwares Accuracy in GPS Observation Processing. Open Journal of Geology, 7, 267-278.

https://doi.org/10.4236/ojg.2017.73019

Received: September 7, 2016

Accepted: March 19, 2017

Published: March 22, 2017

Copyright (c) 2017 by authors and Scientific Research Publishing Inc. This work is licensed under the Creative Commons Attribution International License (CC BY 4.0).

http://creativecommons.org/licenses/by/4.0/

\begin{abstract}
The engineers use various softwares for observation processing and GPS networks, generally everyone who uses a device, he uses softwares with the same brand for the processing of it GPS processing networks by defined default parameters and models. The most outstanding issue is that, it should be understood, the application of which kinds of softwares will help us to gain the desirable accuracy and whether the accuracy of coordinate estimation is acceptable in all commercial softwares or not. In this article, we compared a series of softwares which engineers use for their data processing with powerful scientific software that meanwhile it is too hard and time consuming to learn it. We have considered accuracy and validity of scientific software, which gives acceptable results, as a baseline to see how much errors and difference is between this software and the commercial softwares, so we selected Bernese as a scientific software and LGO, Ashtech Solutions, CGO softwares as commercial softwares and we analyzed them and compared the applied models of the softwares with each other. To do so, we choose a GPS network from Tehran city and discussed it, in order to evaluate the measured accuracy for baselines and also coordinate system that after data processing, it was understood that if the polygon of a network is small, commercial softwares can be utilized with very high acceptable accuracies and even by Ephemerides Precise data, their accuracy will increase more, but if our network is more extended and bigger, there is no other choice except using scientific softwares to calculate coordinate that performs a processing by many parameters.
\end{abstract}

\section{Keywords}

Commercial Software, Scientific Software, GPS, Bernese, LGO, CGO 


\section{Introduction}

In the middle of 1990s, GPS inventors introduced Real-Time Kinematic (RTK) method, that by means of it, we can achieve the desirable accuracies in surveying. In this method, the user usually is in need of a reference station which is located at maximum $10 \mathrm{~km}$ distance, in order to determine the position with centimeter accuracy. The applications of this method account for: positioning with high accuracy for navigation systems, guiding auto-run machines, unmanned aerial vehicles, marine missions like: dredging and large-scale map's update [1]. In general, RTK is a process in which GPS signal corrections are communicated from a reference station's receiver with known position to one or more rover receivers in a real-time strategy [2]. It means that, by short time observations, the determination of dynamic position is possibly prepared and by carrier code signals, the position of rover station is determined with centimeter accuracy immediately [3].

By increasingly development of GNSS satellite navigation and emergence of new companies for production of related receivers, numerous softwares have been developed for processing of these data that in the most general form, these softwares can be divided into scientific and commercial groups. Scientific softwares that mainly are prepared by universities or reliable scientific centers are programmed for utilization in precise and professional tasks. In addition, commercial softwares which are produced by those companies that produce GNSS receivers are applied for data processing of general users and engineers. Commercial softwares not only don't have the complexity of professional and scientific softwares, they have a plain graphical and user friendly environment that it has simplified and quicken dealing with these softwares. While scientific softwares are much more complex and have specific and professional settings that make it too hard to handle them [4]. Nowadays, we are all witness for emergence of many commercial softwares that, it is very crucial to choose the best and the most precise software out of these softwares. Considering the ideas of geomatics engineers, these commercial softwares: CGO, LGO and Ashtech Solutions, are the most used softwares in Iran that we compare this commercial software with a scientific software named Bernese to receive the best answers from comparisons. In this study, we don't aim to describe special software, but the goal is to compare softwares with default methods and an algorithm of softwares. The reason for using the softwares defaults is that, geomantic engineers presented that they don't change any default except the zone of region while working with the softwares. Our theory is that the results and accuracy of scientific softwares is more precise than the results mined from commercial softwares. So our main goal is to compare calculated baselines and estimated coordinate of a process from a network of GPS stations of GNSS servers by scientific and commercial software with each other and conduction of a comparison among commercial softwares, regarding their accuracy in baselines, coordinate and Standard Deviation. Of course, it should be mentioned that, the present softwares or definable 
models for each software will be totally different from each other.

\section{Models of Bernese Scientific Softwares}

In this part, we will introduce various models of this scientific software and we will explain each of them briefly.

\subsection{Offset Model for Antenna Phase Center of Satellite and Receiver}

Offset model of satellite antenna phase and variation of electrical phase of receiver antenna and offset center of receiver's antenna have many effects on PPP processing. So models with ANTEX format have been applied to delete these effects. In Bernese software, ".rel" format is used to omit these effects and in fact, rel. is the ANTEX format of Bernese software. To achieve this format, in addition of using the products of CODE, PHCCNV software can be applied that in Bernese software is prepared for conversion of ANTEX format to ".rel" format [5].

\subsection{Error of Satellite Clock and Error of Satellite Position}

Like other scientific softwares, Bernese software also, uses IGS products to decrease the orbital errors of satellite and the errors of satellite clock, so Bernese software owns this ability to decrease the errors of satellite clocks and errors of satellite clock by using ".clk" and ".sp3" formats. Furthermore, to decrease the orbital errors of satellites, it can use ".sp3" and ".pre” and ".eph" formats too.

\subsection{Model of Relocation from Ocean Upload}

In order to omit the effect of relocation caused by ocean upload, Bernese software uses ".blq" standard suffix of these models. One of the most famous centers that gives these models is Onsala observatory. The users can refer to the website of this observatory and fill the related form to receive these models [6].

\subsection{Earth Rotation Parameters}

Earth rotation parameters are those parameters that are presented in ".eop" standard format. These parameters both are presented by IGS processing center weekly and also they are shown in two (A) and (B) Bultons by IERS. Bulton (A) includes fast earth rotation parameters that are presented daily and Bulton (B) are earth rotation parameters which are published monthly.

\subsection{Satellite State Space Model}

Satellite state space model are models which are released annually by AIUB. These models reveal satellites' safety at different episodes and Bernese software uses these models for proving the satellites' safety at observing time and if satellites' safety is not proved, that satellites' observation would be deleted from observation list [7]. 


\subsection{Satellite Ephemeris Model}

Satellite Ephemeris models are binary files with ".eph" format. These models are presented by solar dynamics observatory, Jet Propulsion Laboratory and NASA. Up to now, three series of these models are presented in these numbers: DE100, DE200 and DE400. Bernese software uses these models to calculate the position of moon, sun and other planets.

Since, the binary format of these models are not free, Bernese software uses a tool to convert numeral format of these models into binary format of Bernese [8].

\subsection{Earth Gravity Model}

Bernese software applies very well-known gravity models like: GEMT3, GEM10N, JGM3, EGM96, TEG4, EIGEN1 and EIGEN2 [9].

\subsection{Ocean Tide Model}

The ocean tide models have ".tid" Suffix that most of them are prepared by space research center of Texas University. Bernese software exploits these models for calculation of variations in gravity caused by oceanic tides.

Note: in scientific softwares, we don't have model for ionosphere and troposphere and the software itself calculates them scientifically [10].

\section{Applied Models in Commercial Softwares}

As mentioned before, in scientific softwares, we don't have any ionospheric and tropospheric errors and the software calculates them scientifically but in commercial softwares, we decrease or omit them by models. In commercial software, we tune the ionosphere error model in automatic state that if the length of network is large, L3 frequency will be used that in this condition, the ionosphere error would be deleted thoroughly but the problem of this work is that the noise is very much. But if the length of network is short, $\mathrm{L} 1+\mathrm{L} 2$ frequency is used that reduces the errors.

\subsection{Applied Models by LGO Commercial Software for Processing}

Parameters and cases that should be set and investigated before processing by LGO software are mentioned in Table 1.

Table 1. Applied models by LGO commercial software for processing.

\begin{tabular}{ccc}
\hline Software & Parameters & Applied amounts and models \\
\hline Leica Geo Office & Tonospheric & Automatic \\
& Tropospheric & Hopfield \\
& Cut off angle & Auto \\
& & $15^{\circ}$
\end{tabular}




\subsection{Applied models by Ashtech Solutions Commercial Software for Processing}

Parameters and cases which should be set and investigated before processing in Ashtech Solutions software are mentioned in Table 2.

\subsection{Applied Models by CGO Commercial Software for Processing}

Some of changeable parameters in CGO software are mentioned in Table 3.

\section{Research Zone}

Selected zones for GPS processing network are from RTK network in Tehran city. Tehran's real-time positioning stations are designed in a way that can cover all 22 regions of Tehran city. In this case study network, we have used 6 regions that (TEHN) is considered as a reference point and others (M804, M318, M022, M020 and TMIC) as rover points. These points of Tehran's City council which are used as permanent stations are chosen. These places are monitored structurally and technically and it is good to say, the points are in a complete safety. Furthermore, to $20 \mathrm{~km}$ distance from each station out of network, it is possible to have access to centimeter accuracy in Single Based format. RTK system is like differential corrections with a difference, this method applies a local reference Base that messages corrections with high accuracy to a rover receiver by radio communication. Thus, the distance and direct vision of base to rover station is an outstanding parameter in this method that causes some limitations while dealing with it, this implies that by increasing the distance of rover station from base one, the accuracy of positioning would face with reduction and the reason is that, ionospheric and tropospheric error models are not equal in different regions and also, it is because of systematic effects on Ephemerids. In fact, limitations such as distance between base and rover stations and mortality of radio

Table 2. Applied models by Ashtech Solutions commercial software for processing.

\begin{tabular}{ccc}
\hline Software & Parameters & Applied amounts and models \\
\hline \multirow{2}{*}{ Ashtech Solutions } & Ionospheric & Automatic \\
& Tropospheric & Hopfield \\
& Frequency & Auto \\
& Cut off angle & $15^{\circ}$ \\
\hline
\end{tabular}

Table 3. Applied models by CGO commercial software for processing.

\begin{tabular}{ccc}
\hline Software & Parameters & Applied amounts and models \\
\hline Ionospheric & Automatic \\
OFFICE & Tropospheric & Saastamoinen \\
& Frequency & Auto \\
& Cut off angle & $15^{\circ}$ \\
\hline
\end{tabular}


waves lead to undesirable accuracy in farther distances and long periods of time and high fees.

A solution that nowadays, is applied in many countries to solve these kinds of problems is to exploit some reference stations and in fact it is formation of a national or local network that sends RTK information and in hence, just by exploiting one GPS receiver, centimeter accuracy is achieved in real-time state. In this method, that is called Network RTK (opposite to the first state that is named Single Base RTK); an unknown station can use one or some known stations (reference) for positioning. The increase in number of reference stations leads to adjustment condition's optimization of observational errors and getting access to more precise results. In fact, the reason for insisting on RTK networking method is that, it can achieve accuracy more than 3 centimeters just only by exploiting one human force. In Figure 1, you can see an outline of the points in urban plan and also satellite images are shown.
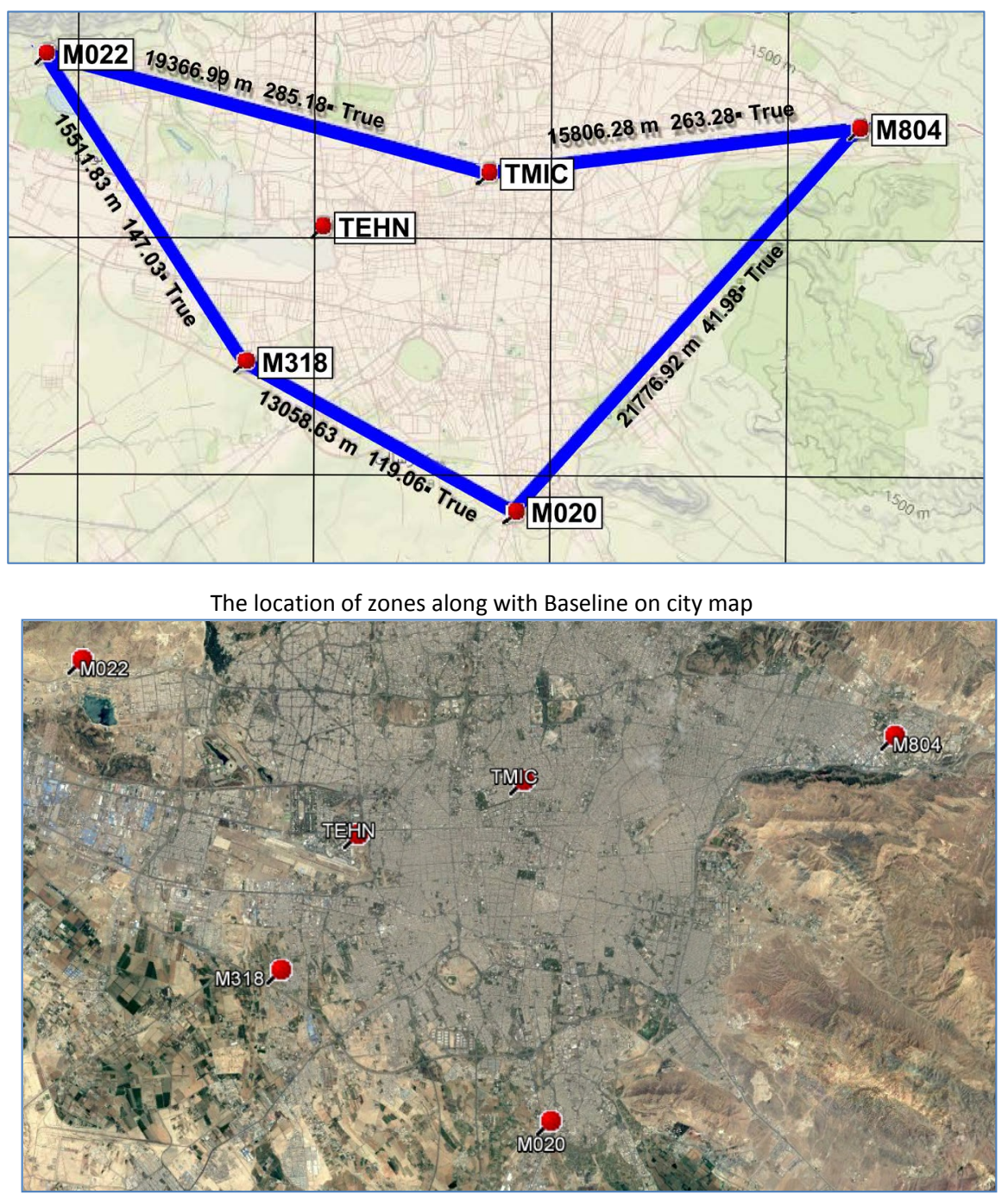

The location of zones on satellite images

Figure 1. Location of these zones in satellite images. 


\section{Numeral Results of Comparison between Commercial Software and Scientific Software}

After entering the information and data to each of softwares, we started to process GPS network that the results are given in Tables 4-6. The results of each commercial software have been compared with scientific software. In these tables, the names of stations and their 3-dimentional positions are mentioned that easily, we can investigate and compare the accuracy of each calculated cases [11].

Table 4. Numeral results of comparison between LGO software and Bernese software.

\begin{tabular}{ccccccccc}
\hline \multicolumn{3}{c}{ Bernese } & & \multicolumn{3}{c}{ LGO } \\
\hline Station & North & East & $\begin{array}{c}\text { Ellipsoidal } \\
\text { Height }(\mathrm{m})\end{array}$ & Station & North & East & $\begin{array}{l}\text { Ellipsoidal } \\
\text { Height (m) }\end{array}$ \\
\hline M020 & 3938414.924 & 538427.672 & 1070.317 & M020 & 3938414.894 & 538427.674 & 1070.370 \\
M022 & 3957711.182 & 518532.650 & 1388.601 & M022 & 3957711.192 & 518532.654 & 1388.702 \\
M318 & 3944720.124 & 526997.869 & 1141.711 & M318 & 3944720.106 & 526997.876 & 1141.771 \\
M804 & 3954660.315 & 552917.907 & 1490.637 & M804 & 3954660.310 & 552917.911 & 1490.714 \\
TMIC & 3952718.767 & 537237.290 & 1295.135 & TMIC & 3952718.978 & 537237.178 & 1295.197 \\
TEHN & 3950425.069 & 530225.958 & 1194.577 & TEHN & 3950425.069 & 530225.958 & 1194.577 \\
\hline
\end{tabular}

Table 5. Numeral results of comparison between Ashtech Solutions software and Bernese software.

\begin{tabular}{|c|c|c|c|c|c|c|c|}
\hline \multicolumn{4}{|c|}{ Bernese } & \multicolumn{4}{|c|}{ Ashtech Solutions } \\
\hline Station & North & East & $\begin{array}{l}\text { Ellipsoidal } \\
\text { Height (m) }\end{array}$ & Station & North & East & $\begin{array}{l}\text { Ellipsoidal } \\
\text { Height (m) }\end{array}$ \\
\hline M020 & 3938414.924 & 538427.672 & 1070.317 & M020 & 3938414.935 & 538427.659 & 1070.255 \\
\hline M022 & 3957711.182 & 518532.650 & 1388.601 & M022 & 3957711.171 & 518532.683 & 1388.610 \\
\hline M318 & 3944720.124 & 526997.869 & 1141.711 & M318 & 3944720.127 & 526997.889 & 1141.667 \\
\hline M804 & 3954660.315 & 552917.907 & 1490.637 & M804 & 3954660.293 & 552917.866 & 1490.610 \\
\hline TMIC & 3952718.767 & 537237.290 & 1295.135 & TMIC & 3952718.757 & 537237.282 & 1295.107 \\
\hline TEHN & 3950425.069 & 530225.958 & 1194.577 & TEHN & 3950425.069 & 530225.958 & 1194.577 \\
\hline
\end{tabular}

Table 6. Numeral results of comparison between CGO software and Bernese software.

\begin{tabular}{|c|c|c|c|c|c|c|c|}
\hline & & & & \multicolumn{4}{|c|}{ CGO } \\
\hline \multicolumn{4}{|c|}{ Bernese } & & \multicolumn{2}{|c|}{ Report of 2D } & \multirow{2}{*}{$\begin{array}{c}\text { Report of } \\
\text { 3D } \\
\text { Ellipsoidal } \\
\text { Height (m) }\end{array}$} \\
\hline Station & North & East & $\begin{array}{l}\text { Ellipsoidal } \\
\text { Height (m) }\end{array}$ & & North & East & \\
\hline M020 & 3938414.924 & 538427.672 & 1070.317 & M020 & 3938414.923 & 538427.671 & 1072.997 \\
\hline M022 & 3957711.182 & 518532.650 & 1388.601 & M022 & 3957711.177 & 518532.647 & 1391.312 \\
\hline M318 & 3944720.124 & 526997.869 & 1141.711 & M318 & 3944720.124 & 526997.869 & 1144.392 \\
\hline M804 & 3954660.315 & 552917.907 & 1490.637 & M804 & 3954660.314 & 552917.905 & 1493.323 \\
\hline TMIC & 3952718.767 & 537237.290 & 1295.135 & TMIC & 3952718.764 & 537237.289 & 1297.814 \\
\hline TEHN & 3950425.069 & 530225.958 & 1194.577 & TEHN & 3950425.069 & 530225.958 & 1197.256 \\
\hline
\end{tabular}


While typing the data of positions to LGO software, the same mentioned parameters in part (3-1) which are the defaults of the software, have been applied but for outputs of Processed data and the final adjustment, the software gives the three dimensional default and extracts $\mathrm{X}, \mathrm{Y}$ coordinates out of reference ellipsoid (WGS84) and reports and by modeling of ellipsoid removal from geoid and regarding to the region's zone, it transfers reference ellipsoid to geoid and gives the correct height of the point compared to the geoid [12].

For Ashtech Solutions software like (2-3) part, to enter data, the same default parameters of software were used and for taking final output from this software, the same strategy of LGO software was applied.

In CGO software, based on the introduced default for the software in part (3-3), the data were entered. But while adjustment for coordinate and achieving the final report of software, it gives two options to user for adjustment: a) 2D adjustment and b) 3D adjustment. When adjustment is carried out two-dimensionally, $(\mathrm{X}, \mathrm{Y})$ coordinate estimation is performed by reference ellipsoid (WGS84) and gives very acceptable results that in Table 6, part CGO and North and East columns, the presented coordinate of two-dimensional adjustment options of software are depicted, but when we select the option of three- dimensional adjustment option, the results both for planimetric coordinate $(\mathrm{X}, \mathrm{Y})$ and height coordinate $(Z)$, they face with marked and significant variations, while in three-dimensional adjustment option, height coordinate is calculated just based on reference ellipsoid and does not give a model for ellipsoid removal from geoid. This means that, $(Z)$ coordinate that should be estimated based on geoid, is calculated by ellipsoid. This subject can be observed by calculated $(Z)$ coordinate that is shown in Table 6 for (TEHN) control point. Of course, this numeral amount is ellipsoid removal in this region that almost, it is a fixed number for all (Z) coordinates in all points.

In following, we can mention to Tables 7-10 that depict the results of calculations of baseline lengths by each software among main stations.

Now, we compare the commercial softwares with scientific softwares that have been as the baseline of research in picture format and by showing the difference amount of $2 \mathrm{D}$ coordinate that the main goal of this paper is to investigate the difference between 2D coordinate and the difference between baseline lengths. The comparison of Bernese scientific software and LGO commercial software for baseline length is shown in Figure 2 and the results of medium difference are presented in Table 11.

Table 7. Baseline length in Bernese scientific software.

\begin{tabular}{ccc}
\hline from & to & Baseline length \\
\hline M022 & TMIC & 19359.436 \\
TMIC & M804 & 15800.360 \\
M804 & M020 & 21768.777 \\
M020 & M318 & 13053.580 \\
M318 & M022 & 15505.726 \\
\hline
\end{tabular}


Table 8. Baseline length in LGO commercial software.

\begin{tabular}{ccc}
\hline from & to & Baseline length \\
\hline M022 & TMIC & 19359.441 \\
TMIC & M804 & 15800.363 \\
M804 & M020 & 21768.796 \\
M020 & M318 & 13053.581 \\
M318 & M022 & 15505.749 \\
\hline
\end{tabular}

Table 9. Baseline length in Ashtech Solutions commercial software.

\begin{tabular}{ccc}
\hline from & to & Baseline length \\
\hline M022 & TMIC & 19359.396 \\
TMIC & M804 & 15800.325 \\
M804 & M020 & 21768.732 \\
M020 & M318 & 13053.548 \\
M318 & M022 & 15505.706 \\
\hline
\end{tabular}

Table 10. Baseline length in CGO commercial software.

\begin{tabular}{ccc}
\hline from & to & Baseline length \\
\hline M022 & TMIC & 19359.437 \\
TMIC & M804 & 15800.359 \\
M804 & M020 & 21768.776 \\
M020 & M318 & 13053.579 \\
M318 & M022 & 15505.723 \\
\hline
\end{tabular}

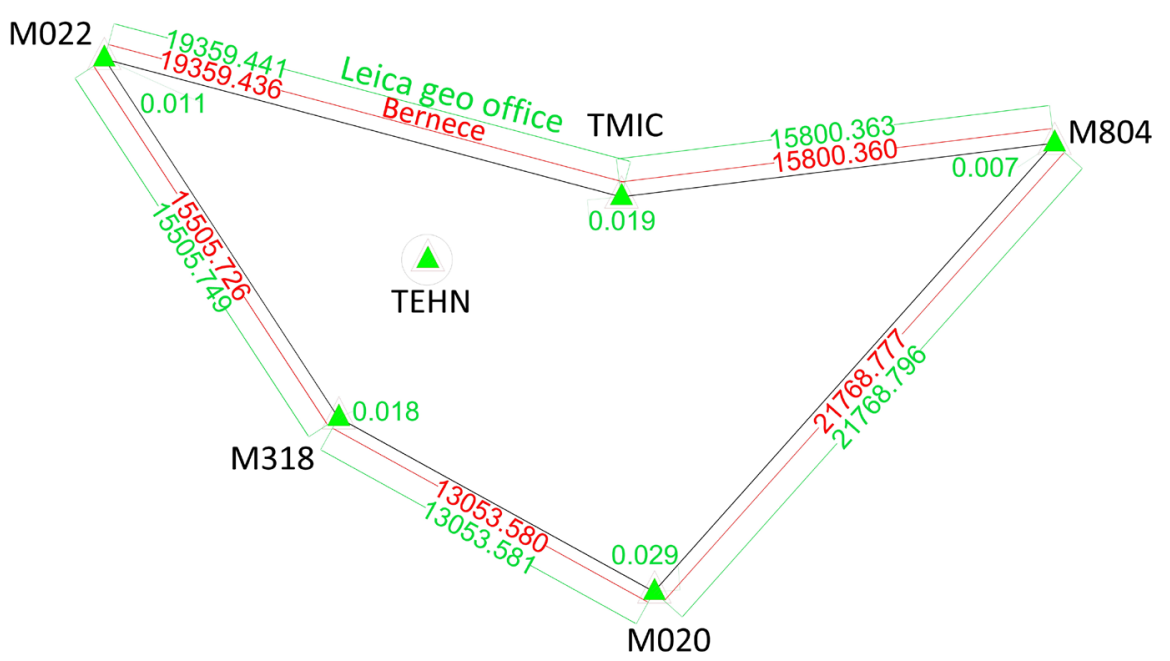

Figure 2. Graphic presentation of comparison between Bernese scientific software and LGO software. 
Also, the comparison of Bernese scientific software and Ashtech Solutions commercial software are presented for baseline lengths in Figure 3 and the result of dimension difference is written in Table 12.

And finally, the comparison of Bernese scientific software and CGO commercial software for baseline lengths are depicted in Figure 4 and the results of dimension difference are mentioned in Table 13.

And at last, it should be mentioned that in planimetric coordinate estimation (X, Y), among commercial softwares, CGO has the best function and its results

Table 11. Comparison of Bernese scientific software results and LGO commercial software at stations dimension.

\begin{tabular}{cc}
\hline Station & $\Delta$ The difference amount \\
\hline M022 & 0.011 \\
TMIC & 0.019 \\
M804 & 0.007 \\
M020 & 0.029 \\
M318 & 0.018
\end{tabular}

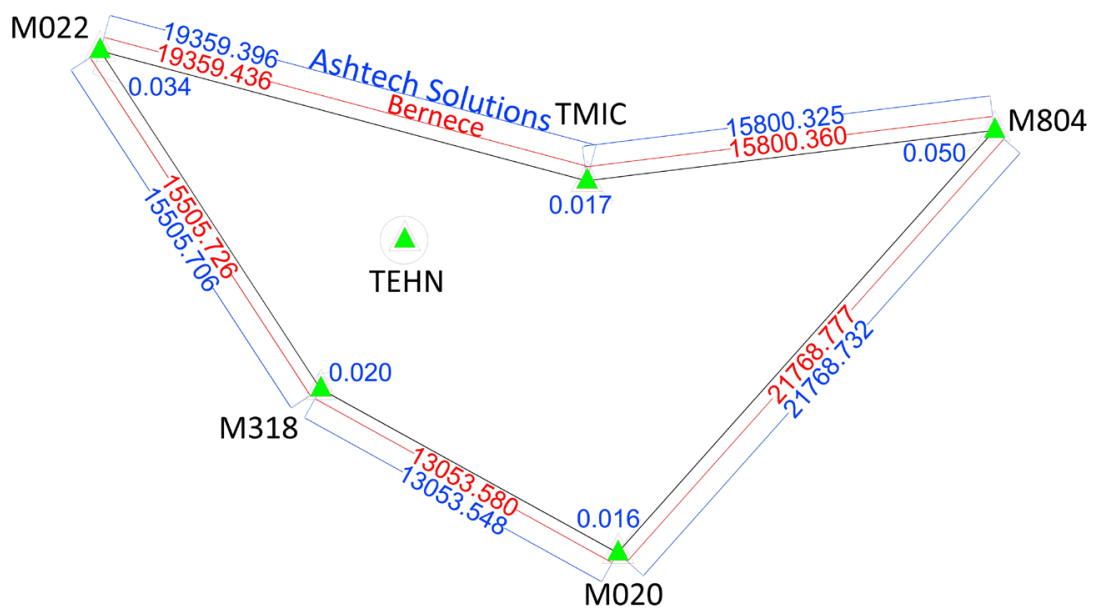

Figure 3. Graphic presentation of comparison between Bernese scientific software and Ashtech Solutions commercial software.

Table 12. Comparison of Bernese scientific software results and Ashtech Solutions commercial software at stations dimension.

\begin{tabular}{cc}
\hline Station & $\Delta$ The difference amount \\
\hline M022 & 0.034 \\
TMIC & 0.017 \\
M804 & 0.050 \\
M020 & 0.016 \\
M318 & 0.020 \\
\hline
\end{tabular}




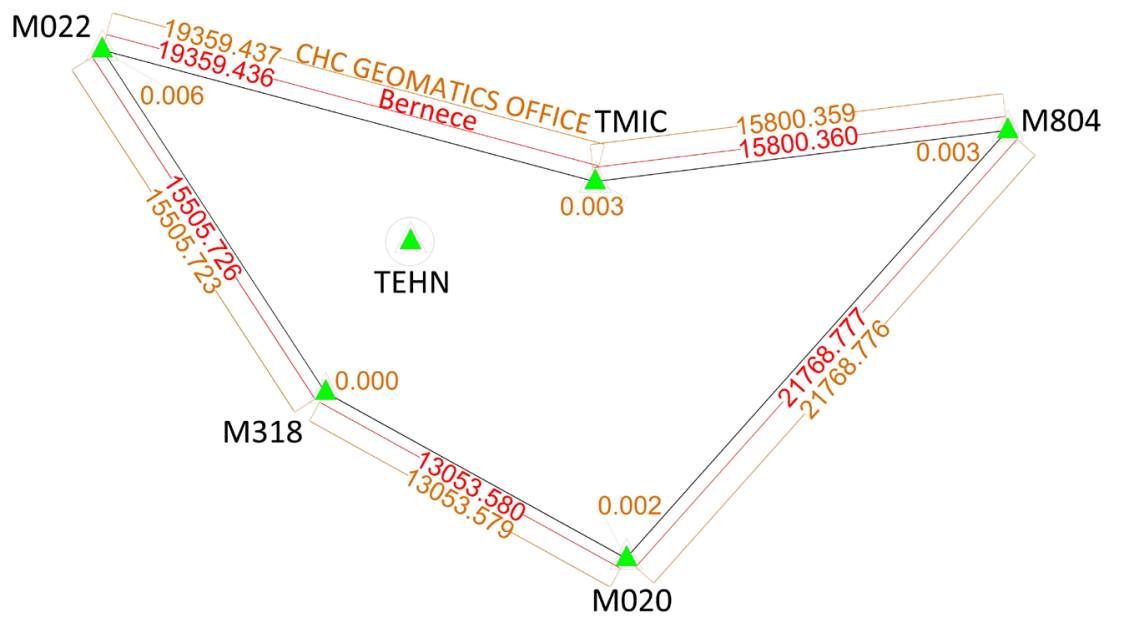

Figure 4. Graphic presentation of comparison between Bernese scientific software and CGO commercial software.

Table 13. Comparison of Bernese scientific software results and CGO commercial software at stations dimension.

\begin{tabular}{cc}
\hline Station & $\Delta$ The difference amount \\
\hline M022 & 0.006 \\
TMIC & 0.003 \\
M804 & 0.003 \\
M020 & 0.002 \\
M318 & 0.000 \\
\hline
\end{tabular}

are very similar and close to Bernese scientific software, but in estimation of height coordinate (Z), Ashtech Solutions software has higher accuracy than other commercial softwares.

\section{Conclusion}

In this research, the goal is not to bold any specific commercial software but it is to compare these softwares with reliable scientific software in order to help the engineers to compare their applied softwares with real results and to know the accuracy of their work. According to the results, it was obvious that commercial softwares just can present acceptable accuracy in small polygons considering their capacity and few numbers of parameters for processing of GPS data and if there is any need for higher accuracy in small polygons amounts, we can achieve higher accuracy (the difference is in mm scale) by entering Ephemerids Precise data after some weeks and for bigger polygons, scientific softwares can be applied because these kinds of softwares are more functional and have numerous parameters for GPS data processing because if commercial softwares are utilized, the results will be unacceptable. 


\section{References}

[1] Instructions for Using the Software (2013) Bernese, Leica Geo Office, Ashtech Solutions. CHC Geomatics Office.

[2] Wang, J., Satirapod, C. and Rizos, C. (2002) Stochastic Assessment of GPS Carrier Phase Measurements for Precise Static Relative Positioning. Journal of Geodesy, 76, 95-104.

[3] Sun, H., Slaughtera, D.C., Pérez Ruizb, M., Glievera, C., Upadhyayaa, S.K. and Smith, R.F. (2010) RTK GPS Mapping of Transplanted Row Crops. Computers and Electronics in Agriculture, 71, 32-37.

[4] Amirkhani, M. (2012) Determination of the Effect of Troposphere Zenith for TwoFrequencies-GPS on Ship. MSc Thesis, University of Tehran, Iran.

[5] Choy, S., Zhang, K. and Silcock, D. (2008) An Evaluation of Various Ionospheric Error Mitigation Methods Used in Single Frequency PPP. Journal of Global Positioning Systems, 7, 62-71.

[6] Yuan, Y., Huo, X. and Ou, J. (2007) Models and Methods for Precise Determination of Ionospheric Delay Using GPS. Progress in Natural Science, 2, 187-196.

[7] Chen, K. and Gao, Y. (2005) Real-Time Precise Point Positioning Using Single Frequency Data. Proceedings of the IONGNSS 18 th International Technical Meeting of the Satellite Division, Long Beach, 13-16 September 2005, 1514-1523.

[8] Bland, J.M. and Altman, D.G. (1986) Statistical Methods for Assessing Agreement between Two Methods of Clinical Measurement. Journal of Lancet, 327, 307-310.

[9] Abd-Elazeem, M., Farah, A. and Farrag, A.F. (2011) Assessment Study of Using Online (CSRS) GPS-PPP Service for Mapping Applications in Egypt. Journal of Geodetic Science, 1, 233-239.

[10] Montazeri, A. and Tahriri, A. (1386) The Analysis and Processing of GPS Data by PINNACLE Software. Zaban Tasvir, Tehran.

[11] Daho, S.A.B. (2010) Precision Assessment of the Orthometric Heights Determination in Northern Part of Algeria by Combining the GPS Data and the Local Geoid Model. Comptes Rendus Geoscience, 342, 87-94.

[12] Péreza, J.L., Mozasa, A.T., Lópeza, A., Aguilarb, B.F.J., Delgadoa, J., Fernándezb, I. and Aguilarb, M.A. (2012) Efficient Methods to Convert LiDAR-Derived Ellipsoid Heights to Orthometric Heights. International Journal of Applied Earth Observation and Geoinformation, 18, 573-578. 
Submit or recommend next manuscript to SCIRP and we will provide best service for you:

Accepting pre-submission inquiries through Email, Facebook, LinkedIn, Twitter, etc. A wide selection of journals (inclusive of 9 subjects, more than 200 journals)

Providing 24-hour high-quality service

User-friendly online submission system

Fair and swift peer-review system

Efficient typesetting and proofreading procedure

Display of the result of downloads and visits, as well as the number of cited articles Maximum dissemination of your research work

Submit your manuscript at: http://papersubmission.scirp.org/

Or contact ojg@scirp.org 